\title{
Protection and Inheritance of Traditional Qiang Settlement Space in Sichuan Based on Sustainable Development*
}

\author{
Ying Meng \\ School of Urban Planning and Architecture \\ Southwest University for Nationalities \\ Chengdu, China 610041
}

\begin{abstract}
The primitive religion and the special ideological value of the Qiang minority have shaped the unique spatial characters of the settlement. How to use the cultural, social and ecological values of these traditional settlement spaces has become an important part of the urban and rural construction in ethnic areas. Based on the theory of sustainable development in harmony, this paper explores the protection and inheritance of traditional Qiang minority's settlement space in Sichuan province. Firstly, this paper is designed to establish dynamic relationship between social, economic and physical space of the settlement and construct a path of inheritance with sustainable development based on the subjective needs of traditional Qiang's settlements. Secondly, based on the pluralistic value of traditional Qiang's settlements, this paper puts forward the idea that only by inheritance of the social value and cultural belief of traditional Qiang's settlements can we protect the value property of traditional settlement space and the diversity of their environment and resources. Thirdly, based on the relationship between society, culture, ecology and settlement space, this paper explores transforming its historical and cultural value to economic capital for villagers' survival, strengthening the way of protection and inheritance by overall use of settlement space.
\end{abstract}

Keywords-Qiang settlement; traditional space; cultural inheritance; sustainable

\section{INTRODUCTION}

Since twenty-first Century, the sustainable development has been the key to the national promotion. In the discussion of the protection and inheritance of the traditional settlement space in ethnic areas, the sustainable development should be integrated into the national development with the era as endorsement. According to the needs of cultural transmission and protection in ethnic minority areas, the path of sustainable development is constructed. The concept of "harmony" of sustainable development can better understand and utilize the overall value of the traditional settlements of the $\mathrm{Yi}$ ethnic group, so that the traditional settlement space of the Yi ethnic group can find a foothold that complements the functions of the city, highlighting the traditional settlement of the Yi ethnic group and the social subject in society and nature. The control relations at different time points can satisfy the needs of more people outside the traditional settlement of the Yi ethnic group, thus ensuring the need for the integrity and dynamic protection and inheritance of the traditional settlements of the Yi nationality.

\section{CONNOTATION OF SUSTAINABLE DEVELOPMENT THEORY}

As soon as the notion of sustainable development was proposed in our 1992 our common future, it quickly became the theoretical framework that guided urban development. Sustainable development has established a coordinated development of society, economy and environment, although it indicates a state in which human society exists, however, the different phases of socio-economic development in different countries lead to different understanding of the objective of the relationship between society [1][2], economy and environment. It is precisely because of the difference between the sustainable development and the value orientation of the subject that causes its concept to be constantly interpreted and analyzed. [3][4] Based on this idea Campbell established a triangular model (Fig. 1) of a sustainable city, trying to solve the city's problems by establishing a set of goals. [5] Later Godschalk revised the model (Fig. 2) on the basis of this and started with the material space to propose a livable urban construction. This "perpetual pyramid" model explains the relationship between sustainable development goals and space and establishes a permanent framework for the development of urban space. However, because of the lack of time latitude and human subjectivity, it has its limitations.

*This paper was supported by China National Scholarship Fund and National Social Science Fund Project "Research on the Protection and Inheritance of Sichuan Qiang Settlements Space Based on the Beliefs of National Belief" (16XMZ045). 


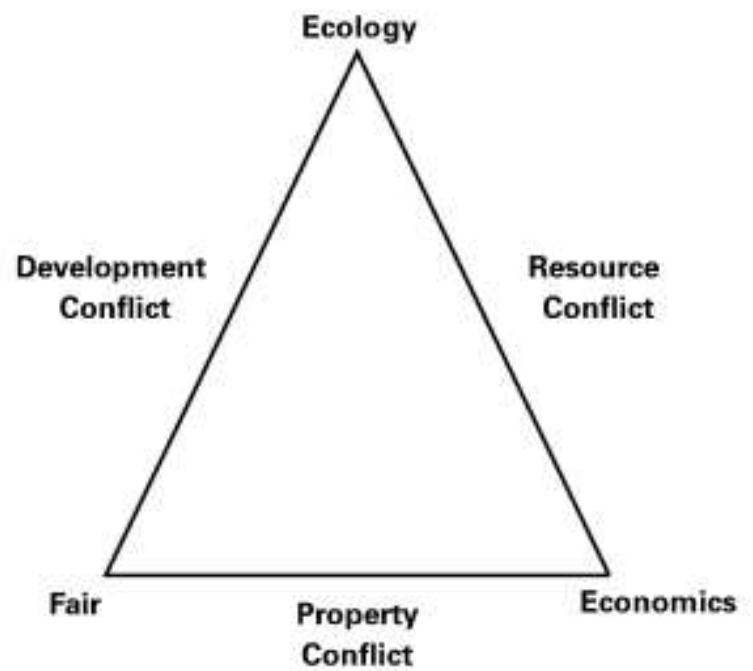

The triangle model of urban sustainable development

Fig. 1. Source: Campbell, 1996.

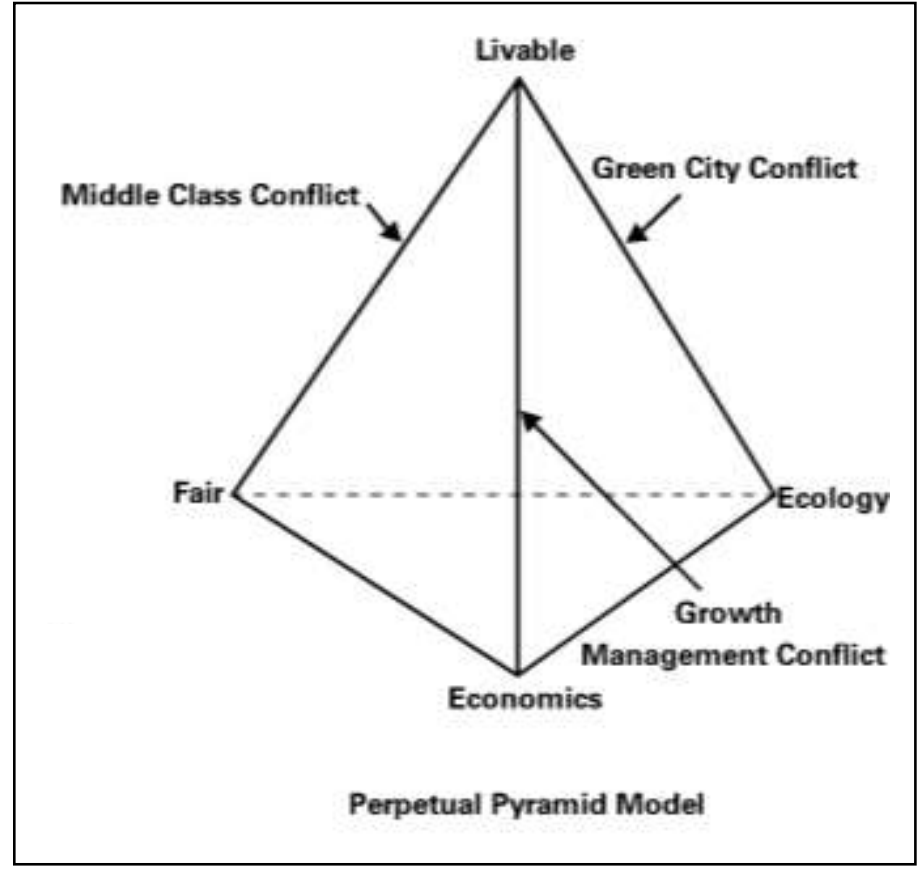

Fig. 2. Source: Godschalk, 2004. 


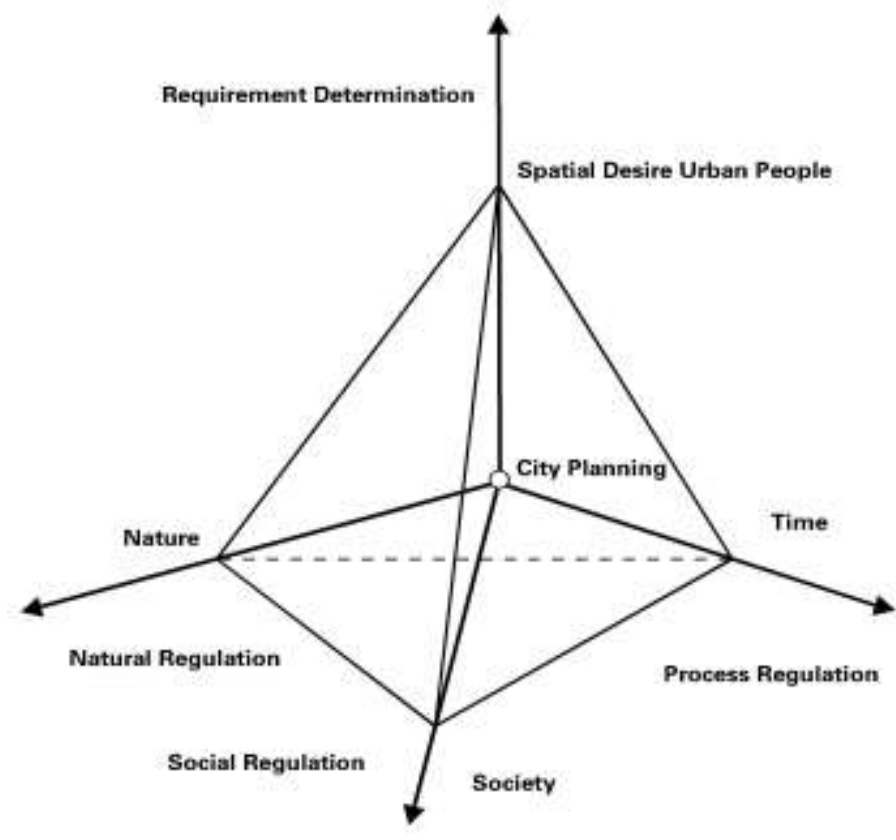

The theoretical model of Harmonious City

Fig. 3. Source: Zhiqiang wu, Chaohui liu, 2014.

Based on the idea of sustainable development, Zhiqiang $\mathrm{Wu}$ and Zhaohui Liu put forward the theory of "harmonious city". (Figure 3) This theory emphasizes the balance control between man and nature, society and time, and emphasizes the state or relationship between man and space at different time points. [7] Based on the subjective needs of human beings, this theory establishes a kind of dynamic equilibrium between material space and human beings. It not only emphasizes the human-centered core idea, but also emphasizes the harmonious relationship between society, economy and environment in long period. The theory also takes the subjective needs of human beings as the starting point, emphasizing the relationship between the settlement groups' living and the ecological environment and keeping their spatial latitudes highly coordinated. This new interpretation of the sustainable development theory emphasizes the controlling of the relationship between the temporal and structural elements of a human being's living space, and points the way for the existence of the material space where human lives in. Although the theoretical object is for the city, its ideas have universal value. Most traditional settlements belong to underdeveloped areas or remote mountainous areas. How to start from the needs of people and use existing cultural space resources to deal with the relationship with time latitude, protecting and inheriting the traditional space elements has become an important part of the process of urbanization.

\section{THE SPATIAL CHARACTERISTICS OF THE TRADITIONAL SETTLEMENTS OF QIANG NATIONALITY}

\section{A. Cultural Spatial Attributes of Qiang Traditional Settlements}

Traditional settlements of Qiang nationality in Sichuan are mostly distributed in the mountain valleys of the upper reaches of the Minjiang River. They are rich in multi-faith deity and original worship culture. For thousands of years, the villagers have lived in the depths of the upper reaches of the Minjiang River and still retain the original polytheism. The Qiang ethnic group holds that all content related to the daily life of human beings is dominated by the gods. Qiang ethnic that people from nature, and ultimately will return to nature, so they treat each element of the natural environment, determines their treatment of the natural values and emotional attitude. In the daily life of the Qiang people, their beliefs and worship of heaven, earth, Japan, the moon, mountains, water and the natural environment can be seen everywhere. The Qiang nationality not only set up temples, stone pagodas, stone pagodas, sacred stone and other religious carriers in the settlements, but also built Lekexi worshiping on the roofs of buildings and set gods such as fire dragon god, horn angel, and god of fire god in the family space.(Fig. 4) These contents form a unique cultural type and spatial form of the traditional settlements of Qiang ethnic groups in Sichuan, and become a beautiful cultural landscape of the traditional settlement in the upper reaches of Minjiang River. 


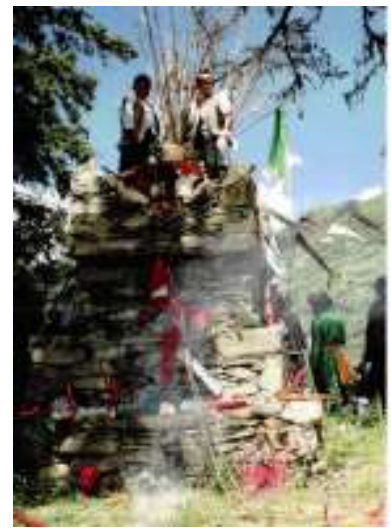

Fig. 4. Qiang belief, source: Lixian County Tourism.

\section{B. The Social Spatial Attributes of Qiang Traditional Settlements}

Unique social space attributes and functions. The upper reaches of the Minjiang River valley is the only way to connect the Hexi Corridor with the Chengdu Plain. Since ancient times, it has been an important channel for national migration. The big and small battles for survival are accompanied by the migration of the nation, the Minjiang River valley naturally become a war-prone place. This external social and historical conditions and the inherent natural environment of the alpine gorge shape the long-term living conditions of the Qiang people, and also shape the social unity of the ethnic Qiang ethnic group and maximize

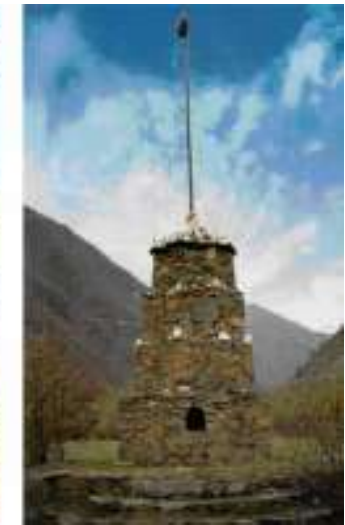

the social concept of using space resources and environment. In order to save land, Qiang ethnic minority households try their best not to occupy grain fields, publicize the function of family space, ethnicize the channels between families, and form a roof platform connected with each other, with similar households and different heights Social interaction space. This approach not only meets the needs of the daily life of exchanges, but also to create a common household contact and defense channel in "Fig. 5". Therefore, Qiang people's settlement space exists a kind of state that is in harmony with the natural environment, unique in cultural representation and harmonious in the spatial texture, which is precious in the space culture of traditional settlement in China and has become a rare and important cultural heritage.

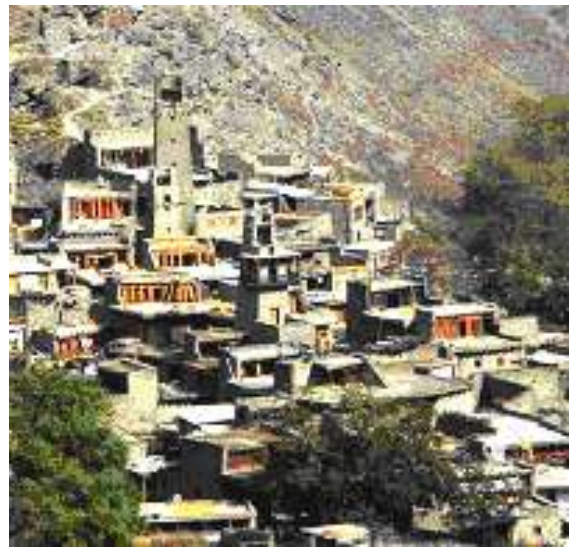

Fig. 5. Roof terrace of Tao Ping Qiang Village. Source: Lixian County Tourism Bureau.

\section{Natural Spatial Attributes of Qiang Traditional Settlements}

Adapt to nature and the perfect combination of terrain characteristics. The upper reaches of the Minjiang River belong to the typical alpine valley geography environment. The climate of the arid valley and the warm mountain climate form a huge contrast. At the same time, due to the rich mountain land resources, the Qiang nationality settlements are mostly distributed in the upper half of the mountain or the mountain. In order to adapt to the living environment, they selected local materials, building materials, Jing grass and mud masonry to build three to five carvings, watchtowers up to several meters. To ensure the stability of the building, the wall naturally converges from the foundation to the top in "Fig. 6". The Qiang Watchtower stands among the valleys, preserving the unique construction skills of the Qiang people and becoming the spiritual symbol of the Qiang people's settlement space. The layout of Qiang buildings along the contour lines and the use of topographic changes of the natural elevation form functional spaces of different floors, which not only reduces the earthwork filling and excavation but also increases the space used area, and also ensures the organic organization of the entire settlement space. The Qiang traditional settlement within the street fully use the mountain water system to open the space, as far as possible to reduce the adverse effects of strong winds, forming a spatial combination with the terrain texture. It is 
precisely because Barrier and inconvenient traffic conditions in the alpine valley make the settlement of Qiang mostly hidden in the natural environment and muddy with Yamagata and other natural elements.
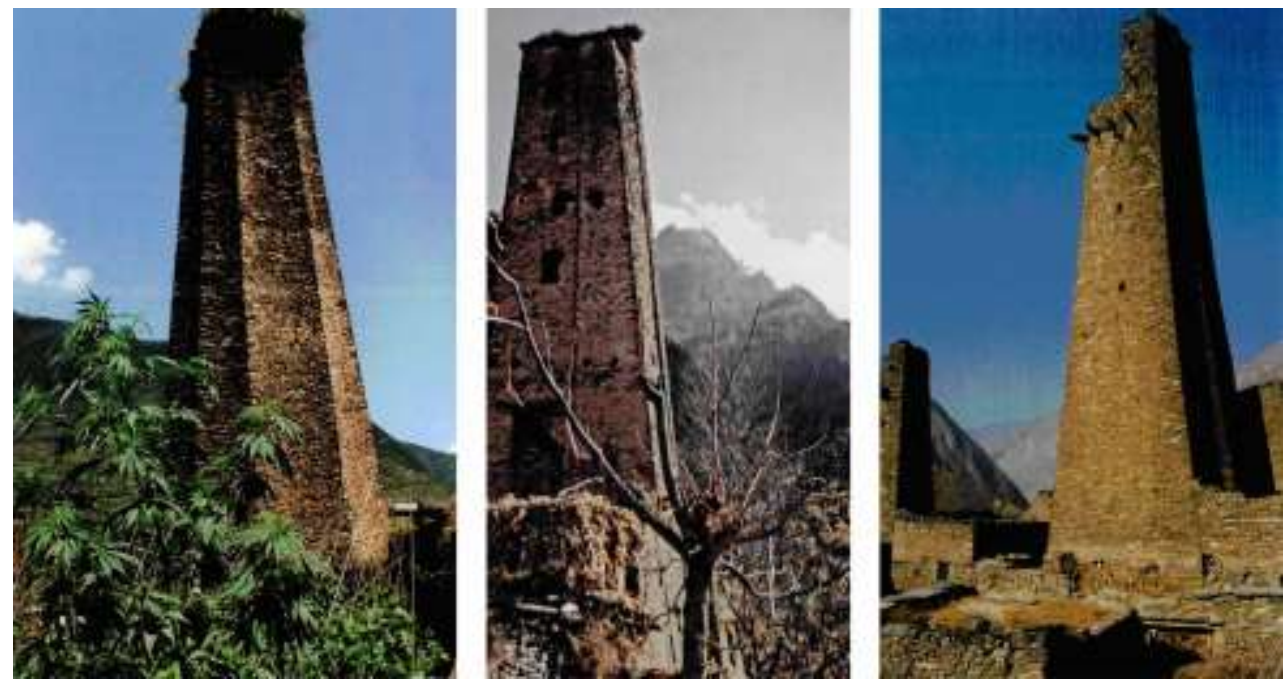

Fig. 6. Qiang tower, Source: Lixian County Tourism Bureau.

\section{The Defense Spatial Characteristics of Qiang Traditional Settlements}

A three-dimensional network of space defense systems. Scholars such as Guangrong Ran described in the "History of Qiang" that the Qiang nationality was a shepherd distributed throughout western China. According to "Li county" records, the upper reaches of the Minjiang River Qiang race with local people in the process of survival of living space, [8] has experienced all kinds of big and small battles[9]. In such a social and historical environment, in order to safeguard their own safety and make full use of the natural terrain, the Qiang nationality not only built defensive carvings and carved houses, but also used public tunnels and roof platforms as a defensive function, thereby forming a complex of towers, towers, Roadway and roof platform composed of tight threedimensional defense system. Not only in the bottom of the formation of interlaced internal roadway, also formed in the top of the same household escape routes. (Figure 7)This kind of relying on blood and value recognition intertwined space, shaped the social function of settlements, highlighting the harmonious social relations and spatial organization of the Qiang ethnic group. Therefore, the living space of the Qiang people is a kind of living wisdom that is endogenous to the environmental villagers in the organic combination of culture, society and nature while the defense space is the superb combination of the social space organization formed by the villagers and the terrain environment in response to external threats to survival skill.
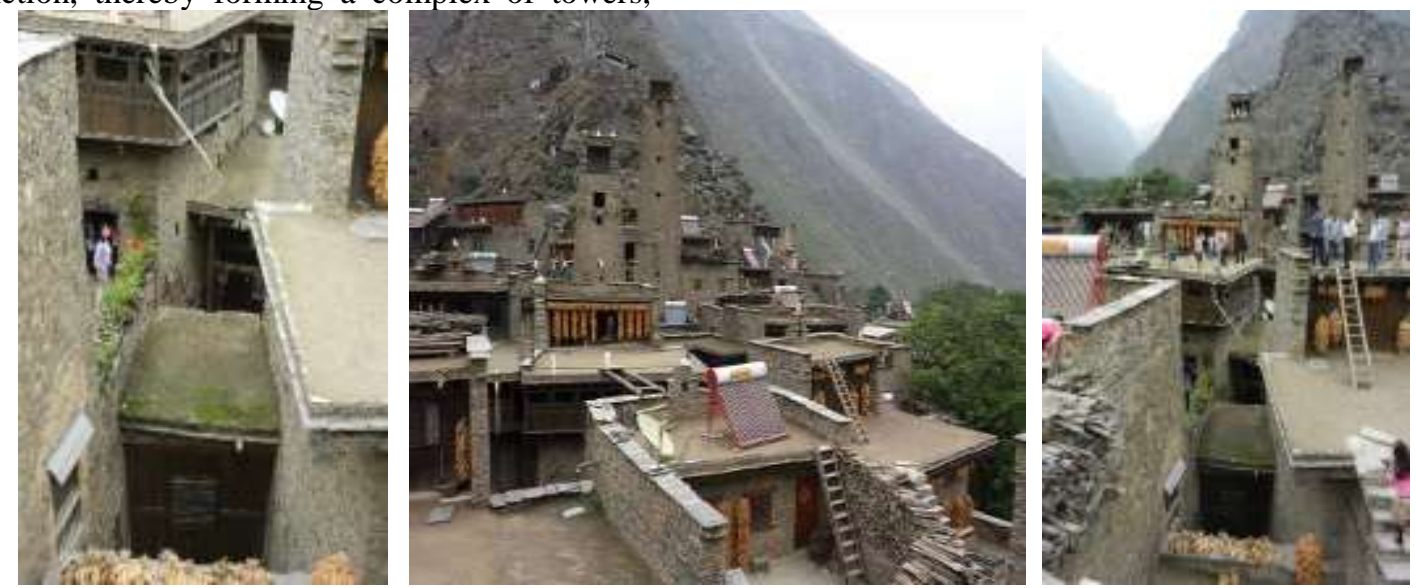

Fig. 7. County Taiping Qiang Walled,source: Self-photo. 


\section{The Space Situation of the Traditional SETTLEMENT OF THE QIANG PEOPLE IN SichuAN}

\section{A. The Social and Economic Conditions of the Qiang Traditional Settlements}

The traditional settlements of Qiang nationality in Sichuan are mainly located in the upper reaches of Minjiang River in Wenchuan, Maoxian, Li County and Songpan, and the transition zone from Sichuan Basin to Qinghai-Tibet Plateau. The traditional settlements of Qiang mostly distribute the Mid-levels between 1800 and 3200, with rare cultivated land. ${ }^{[10][11]}$ After the eighties of last century, the government implemented the relocation of various types of projects, and the traditional settlements after the relocation gradually became sites and monuments such as Luoshan and Rugao Straits in Ruili County in "Fig. 8". The construction art of these new settlements has lost its tradition. The settlement space with the traditional value orientation of the Qiang people has been replaced by a fragmented vertical form of space dominated by individual values. The settlement space organization has lost its original organ city and ecology Sexual and ethnic. ${ }^{[12]}$ However, for those traditional settlements still in the mountains with inconvenient transportation, the villagers still continue the traditional mode of production and still live a lower standard of living.

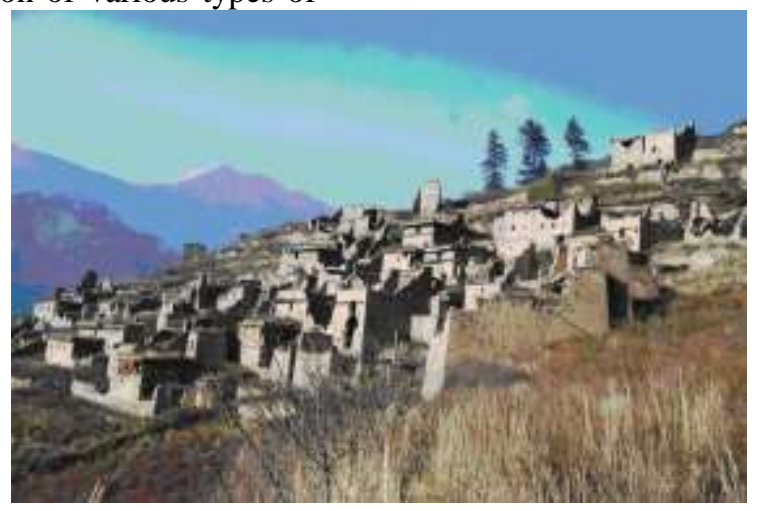

Fig. 8. Luoshan Lixian, Source: Lixian County Tourism Burea.

\section{B. The Impact of Urbanization on the Traditional Settlement Space of Qiang People}

Urbanization leads to the decline of the social culture of the traditional Qiang ethnic group. The population flow brought Long-term living in the mountains among the Qiang villagers also urgently need to enjoy the civilized life brought by social progress, so a large number of Qiang went out of the mountains to the city. The new mode of production not only affected the cultural value of the traditional settlement space but also changed the social organization relations, leading to the decline of the traditional settlement culture and the social culture carried by people. The clear water of the mountainous upper reaches of the Minjiang River contains a huge amount of power resources and has led to the growth of large and small hydropower stations. The reservoirs formed as a result of the construction of power stations inundated many traditional settlements and triggered many secondary disasters. This situation has led many villagers to lose their land for survival and to change the ecological and cultural environment of the Qiang traditional settlement space. This has exacerbated the hardship of villagers living in the mountains.

\section{The Negative Effect of Post - disaster Reconstruction on the Traditional Settlement Space of Qiang People}

The 5.12 earthquake in 2008 caused the traditional settlement of Qiang ethnic groups to suffer serious disasters. The government led a large-scale post-disaster reconstruction. With a mere investment of more than 70 billion yuan, it became a settlement space with the most extensive influence, the most concentrated time and the most abundant participation. Villagers relocated off-site by the government's leadership. They broke away from their original living environment, led to the collapse of the social structure formed in the long history, no longer existed the basis for the traditional settlement of spatial features, and the original spatial characteristics of settlements were gradually disappearing. Although many scholars pay attention to the post-disaster reconstruction mode[13], reconstruction process[14] and space culture[15] from different perspectives, some scholars pay attention to the operation[16] of postdisaster reconstruction funds. However, few scholars evaluate the social, cultural and ecological value of postdisaster reconstruction settlements and few scholars evaluate cultural identity and spiritual needs of Qiang villagers for the original settlement space of Qiang's traditional settlements.

\section{PROTECTION AND INHERITANCE OF SPACE FOR TRADITIONAL SETTLEMENTS OF QIANG NATIONALITY BASED ON SUSTAINABLE DEVELOPMENT}

\section{A. Establishing a Dynamic and Harmonious Target Is the Prerequisite for the Sustainable Heritage of Traditional Settlements}

Through field research, it is found that there are obvious differences in the needs of economic development, living environment and social harmony between Qiang villagers in different economic positions, resulting in different problems and conflicts in different traditional settlements in "Fig. 9". To protect and inherit the material space of the traditional 
settlement of Qiang people, we must firstly meet the needs of human beings. Therefore, we must firstly address the needs of different settlement villagers, protect the value of traditional settlement space, and set demand targets for different stages according to the needs of different groups. For example, Qiang traditional settlements which have strong demand for economic development, Externalize the values of the various cultural forms of settlement. Under the premise of not destroying the ecological environment of settlements, the social and cultural resources of the Qiang ethnic settlement space should be protected and utilized. For those Qiang traditional settlements that require a high degree of living environment and harmonious living, the social and human relations between the traditional settlement space and the villagers are protected as much as possible, so that their spatial values are highly recognized within the settlement groups and thus self-protection can be achieved. For those Qiang traditional settlements that require a high degree of living environment and harmonious living, the social and human relations between the traditional settlement space and the villagers are protected as much as possible, so that their spatial values are highly recognized within the settlement groups and thus self-protection can be achieved.

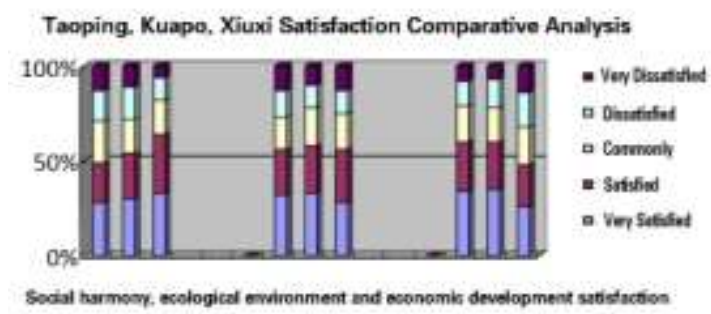

Fig. 9. Traditional Qiang Village Satisfaction Survey. Source: self-drawing.

\section{B. Achieving Cultural Social Identification Is at the Heart of the Sustainable Heritage of Conservation and Traditional Settlement}

Culture is a kind of existence that transcends material space and human life. Its ideological concept and social value, which lead the construction of settlement space, has led the social existence of settlement groups and the cultural and social value of material space, and has become the core of the traditional settlement space for Qiang people value. The objective social and historical processes, the differences in geographical environment and the diverse needs of different ethnic groups in the Qiangs jointly shaped the diverse cultural forms of settlement space. Because of its unique multi-cultural forms different from other settlements, it shows its value position in society. The needs of society create opportunities for the economicization of the spatial cultural values of the traditional settlements of the Qiang people, and at the same time enable the traditional settlement of Qiang people to realize their respective functional complements in the spatial, resources, environment and historical and cultural values, and realize the increase of villagers' income through the tourism industry.

The protection of traditional cultural values of the Qiang nationality as the heritage of the entire community to identify,
This approach should be adjusted in time with changes in the needs of villagers. The essence of this approach is to realize the inheritance and protection of Qiang ethnic settlement space by establishing a dynamic target of economic development with excellent environment and social harmony. Its basic idea is to base itself on the social needs of the settlements of the Qiang people and to turn the value of the traditional settlement space into capital for economic development. The following specific way: to integrate the value of Qiang traditional settlements into higher-level industrial functions, achieve greater spatial resource integration, and drive the all-round economic development and social harmony and stability. Using the structural relations among traditional settlements of Qiang ethnic groups, establish perfect social organizations and cultural functions, meet the needs of historical and cultural settlements in certain areas and maximize the value of their national culture. In view of the scattered nature of the traditional settlement of Qiang nationality, it is necessary to strengthen the organic relations among each other and to achieve the balance control of resources in the latitude of space, environment and society.

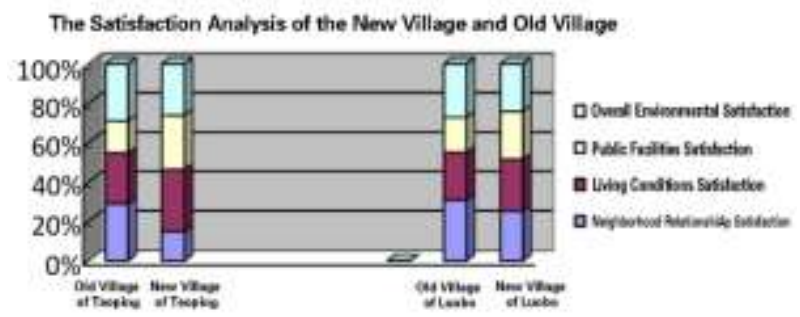

so as to promote the economic settlement within the traditional settlement of society, economy, environment and space. This is based on using cultural values as a social resource and using economy as a means of traditional settlement development in Qiang, placing a balance of control over time and space through the needs of traditional settlement groups. This mode of utilization relies on the guidance of the relationship between social needs and settlements economy so as to promote villagers' protection of the cultural values of traditional settlements. Therefore, while protecting the historical and cultural values of traditional settlement space, utilizing historical and cultural values to promote the social and economic development of traditional settlements, it is necessary to strengthen the temporal relationship between the subject of protection and inheritance.

\section{The Establishment of a Holistic Concept of Protection Is an Effective Way to Inherit the Sustainable Development of Traditional Settlements}

The fragile natural environment and the unique history of the Qiang people's living space have maintained the villagers' ways of getting along with the natural environment for a long time and also shaped the highly dependence 
between their unique cultural forms and the space environment. Under the premise of ensuring the ecological environment is not destroyed, the overall protection of the Qiang traditional settlement space is to maximize its value. In the upper reaches of the Minjiang River, there is not much available resources in the mountainous area. If based on the traditional settlement of the overall value of space, you can reduce a single building or settlement cannot form a scale effect of the defects, so as to enhance the traditional settlers and nature in the social, economic and environmental values. The overall protection of the Qiang ethnic settlements makes it easier for the settlement villagers to recognize their own values, and through its intergenerational effect, to achieve a better inheritance so as to ensure that the Qiang traditional culture with space as its carrier has the vitality for sustainable development.

The integrity of the Qiang traditional settlement space includes not only the villagers' living space, production space and the cultural forms of material space, but also the organizational relations among the space elements, the cultural relations between the living space and the surrounding mountainous environment, and the ecological concepts of these space elements Wait. The historic, social, spatial and distinctive features of the traditional settlements are reflected in the interdependent organizational relationships between the elements and the fragmentation of any part of them reduces their value attributes. The integrity of the settlement space covers the social, historical and humane values of the Qiang ethnic group. The systematic nature of its elements best embodies all the material and spiritual needs of the Qiang people. Its overall systematic also highlights the villagers' wisdom in dealing with various living relationships. Taking the protection of the integrity value of Qiang settlement space as a breakthrough, it is easier to form the relationship control between the timeliness and structural elements of the Qiang people's living space.

\section{CONCLUSION}

The traditional settlement space of the Qiang people is an important part of the human historical and cultural heritage. Facing the situation of the traditional settlement space of the Qiang people, it is necessary to meet the needs of the settlement groups. At the same time, we should not only embody the value of the traditional settlement space, but also realize the need of the combination of society, economy and good ecological environment. The idea of "harmony" for sustainable development has clear objectives and modes of implementation so that the material space of the Qiang people's traditional settlement and the needs of human beings represent a harmonious society, nature and settlement in terms of time and space.

The traditional settlement space of the Qiang nationality is a product of the Qiang ethnic culture and history. To maximize its value, it is necessary to give play to its significance in real life. According to the dynamic needs of human being in "harmonious" theory, the dynamic target of economic, social and environmental harmonious development is to protect the cultural values of settlement groups as the core. By adjusting the physical space elements into the economic, social and natural environment in time, help to take the classified development mode and the improvement measures, so as to establish and perfect the policy system of protection and inheritance mechanism, to maximize the protection of the original settlement space habitat and the whole value. The theory of "harmony" based on the theory of sustainable development provides a clear direction for the development of traditional settlements

The concept of "harmony" in sustainable development can better understand and make use of the overall value of the traditional settlement of Qiang ethnicity, and make the Qiang traditional settlement space find a foothold complementary to the city's function. It highlights the control relationship between the traditional settlements of the Qiang nationality and the social subjects at different time points in society and nature, and meets the needs of more people besides the traditional settlements of the Qiang nationality, thus ensuring the need for the protection and inheritance of the integrity and dynamics of the Qiang traditional settlements. The harmonious relationship between society, environment, economy and human beings has found a combination of points in space. It also correspond to the corresponding time and space in different stages of human beings, and lay a theoretical foundation for the heritage and protection of the traditional settlement space of the Qiang people.

\section{ACKNOWLEDGMENT}

To speed up the post-disaster reconstruction of the earthquake-stricken areas and make the counterpart support work in various places in an orderly manner, the General Office of the State Council promulgated the "Countervailing Support Program for the Post-Wenchuan Earthquake Rehabilitation and Reconstruction" on June 11, 2008. Staterun hair [2008] NO.53

From the beginning of May 2011, the Qiang population distribution in Beichuan and Pingwu, Wenchuan, Maoxian, Songpan, Jiuzhaigou, Lixian, Blackwater, Kim, Daofu and other places to carry out data collection and field survey, collected a lot of first-hand information. Among them, the six traditional Qiang settlements, including township Wenchuan county dragon village, Kua Po village, Lixian Pu Xi Xiang Hugh Xi Cun, Tao Ping Xiang Tao Ping Cun, Zeng village, village $\mathrm{Mu}$ Qia $\mathrm{Mu}$ Qia Xiang conducted a questionnaire survey and structured interviews and field reconnaissance, interviews with 26 villagers, there are managers, the family, the subject and the ethnic composition are Qiang Shibi. At the same time, they also visited local culture, construction and other relevant departments, and interviewed 42 people from the government department.

\section{REFERENCES}

[1] Dajian Zhu. Sustainable Development [M]. Shanghai: Tongji University press,2013

[2] Hongwei Sun. Environmental Protection and Sustainable Development of the Theory and Practice[M]. Beijing: Xueyuan press, 2014 
[3] Artur Pavlovskiy, Ling Li. Sustainable Development Revolution [J]. Shenzhen: Journal of Shenzhen University (HUMANITIES AND SOCIAL SCIENCE EDITION), 2013 (06): 44-47

[4] Longxi $\mathrm{Li}$. Interpretation and analysis of the theory of sustainable development [J]. Shenzhen: Administration and law, 2005 (01): 3-8

[5] Campbell S. Green cities, growing cities, just cities? urban planning and the contradictions of sustainable development[J]. Journal of the American Planning Association, 1996 (03) :296-312

[6] Godschalk D. Land use planning challenges: coping with conflicts in sustainable development and livability community visions $[\mathrm{J}]$. Journal of the American Planning Association, 2004 (01) :5-13

[7] Zhiqiang Wu, Chaohui Liu. "Harmonious city": the city planning theory model of city planning [J]. journal, 2014 (03): 12-19 Guangrong Ran, Shaoming Li, Xiyin Zhou. History of the Qiang people [M]. Chengdu. Sichuan national press, 1985

[8] Guangrong Ran, Shaoming Li, Xiyin Zhou. History of the Qiang people [M]. Chengdu. Sichuan national press, 1985

[9] Lixian Chronicles. Lixian Zhi [M]. Chengdu: Sichuan national press, 1997

[10] Minqiu Shi, Qing Wang, Yalin Guo, Yu Zhang. Analysis of the spatial distribution of settlements in the upper reaches of the Minjiang River [J]. Journal of Southwest University of Science and Technology, 2014 (12): 33-37, 81

[11] Qing Wang, Minqiu Shi, Yalin Guo, Yu Zhang. Study on vertical differentiation of settlements in mountain areas of the upper reaches of Minjiang River [J]. Journal of geography, 2013 (11): 1559-1567

[12] Yanguo Liu, Chengmin Huang, Qing Wang, Li Wang, Qiang Zou. An empirical study on the change rule and driving mechanism of settlements in the area of the hybrid River in the upper reaches of Minjiang River, [J]., Journal of Hainan Normal University (NATURAL SCIENCE EDITION), 2014 (03): 57-62

[13] Peng Ye, Jie Chen. Investigation and study of urban housing reconstruction model after 512 earthquake disaster in Dujiangyan City, [J]. Central China Construction, 2010 (02): 32-34

[14] Shiwen Sun, Tao Zou. Public participation in planning, promote post disaster reconstruction -- Based on Dujiangyan city housing reconstruction process [J]. city planning forum, 2010 (3): 75-80

[15] Ruishan Zheng, Qian Bao. Realistic problems and Reflections on the reconstruction of Wenchuan earthquake after the earthquake disaster [C]. China Chongqing.2010 China urban planning annual meeting paper, 2010:1-5

[16] Huaheng Chen, Yuansheng Jiang, Yufeng Wang. Operation mechanism, problems and Countermeasures of capital construction of Wenchuan after earthquake disaster[J]. Policy Research, 2010 (11) : 21-23 